(NASA-TM-111213) ASSESSMENT OF N96-17184 MICROALLOYING EFFECTS ON THE HIGH TEMPERATURE FATIGUE BEHAVIOR OF NIAL (NASA. Lewis Research Center) $6 \mathrm{p}$ 


\title{
ASSESSMENT OF MICROALLOYING EFFECTS ON THE HIGH TEMPERATURE FATIGUE BEHAVIOR OF NiAI
}

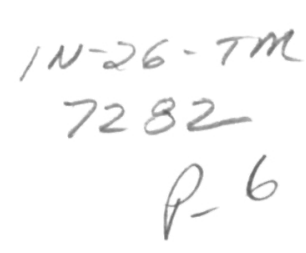

\author{
R. D. NOEBE, B. A. LERCH, AND K. BHANU SANKARA RAO* \\ NASA Lewis Research Center, Cleveland, OH 44135 \\ *NRC Associate, NASA-LeRC
}

\begin{abstract}
Binary NiAl suffers from a lack of strength and poor creep properties at and above 1000 $\mathrm{K}$. Poor creep resistance in turn affects low cycle fatigue (LCF) lives at low strain ranges due to the additional interactions of creep damage. One approach for improving these properties involves microalloying with either $\mathrm{Zr}$ or $\mathrm{N}$. As an integral part of a much larger alloying program the low cycle fatigue behavior of $\mathrm{Zr}$ and $\mathrm{N}$ doped nickel aluminides produced by extrusion of prealloyed powders has been investigated. Strain controlled LCF tests were performed in air at $1000 \mathrm{~K}$. The influence of these microalloying additions on the fatigue life and cyclic stress response of polycrystalline $\mathrm{NiAl}$ are discussed.
\end{abstract}

\section{INTRODUCTION}

It is evident from the substantial research that has been performed on binary NiAl over the years that this intermetallic is deficient as a structural material in at least two areas: low temperature ductility and high temperature strength $(1,2)$. Therefore, any useful structural alloy based on $\mathrm{NiAl}$ will contain at least microalloying additions if not macroalloying additions to alter or enhance these critical properties $(3,4)$. The effect of microalloying additions on properties can range quite significantly in $\mathrm{NiAl}$ alloys. A few microalloying ( $<1$ at.\%) additions such as $\mathrm{Fe}$ and $\mathrm{Ga}$ can have a mildly beneficial effect on the tensile ductility of $\mathrm{NiAl}$ single crystals (5) but have essentially no impact on the properties of polycrystalline alloys (6). Most other microalloying additions decrease the already limited low temperature tensile ductility and increase the brittle-toductile transition temperature of $\mathrm{NiAl}$ (2). A number of additions such as $\mathrm{Zr}, \mathrm{Hf}$, and $\mathrm{Ti}$, while detrimental to low temperature properties, can have a moderate to very significant strengthening effect at elevated temperatures (2,3,7-9). However, at least one alloying addition, nitrogen, tends to have a mildly positive effect on both the creep resistance (10) and low temperature tensile ductility (11) of polycrystalline NiAl.

Of the various microalloying additions, $\mathrm{Zr}$ has been studied in significant detail due to its extremely dramatic impact on the behavior of $\mathrm{NiAl}$. $\mathrm{Zr}$ additions decrease the already limited room temperature tensile ductility of polycrystalline $\mathrm{NiAl}$ and significantly increase the brittle-toductile transition temperature (BDTT) $(6,12)$. The increase in BDTT was attributed to the segregation of $\mathrm{Zr}$ to the grain boundaries (13) and the subsequent inhibition of localized deformation mechanisms that are necessary for meeting the Von Mises criterion, and therefore, limiting tensile ductility (14). These deformation studies also indicated that $\mathrm{Zr}$ was an extremely potent solid solution strengthening agent. This led to a detailed study of the high temperature deformation behavior of $\mathrm{NiAl}(\mathrm{Zr})$ alloys which indicated that even the smallest $\mathrm{Zr}$ additions 
(0.05 - 0.1 at.\%) resulted in alloys that were several times stronger than binary $\mathrm{NiAl}$ under identical conditions of temperature and imposed strain rate (9).

However, the effect of $\mathrm{Zr}$ or other microalloying additions on the cyclic deformation behavior of $\mathrm{NiAl}$ has not been previously investigated. The studies already described would indicate that $\mathrm{Zr}$ should have both beneficial and detrimental effects on the cyclic behavior of NiAl. For example, the fatigue life of binary $\mathrm{NiAl}$ is superior to most structural materials at $1000 \mathrm{~K}$ compared on a plastic strain range basis due to its high ductility (15). Therefore, $\mathrm{Zr}$ would tend to reduce this advantage since the ductility of $\mathrm{Zr}$-doped $\mathrm{NiAl}$ would be much lower. On the other hand, the fatigue life of $\mathrm{NiAl}$ is inferior to superalloys on a stress range basis because of its low flow stress. $\mathrm{Zr}$ would probably be beneficial in this regard. In addition, fatigue failure of binary $\mathrm{NiAl}$ was attributed to an environmentally assisted fatigue damage mechanism that was aggravated by extensive grain boundary void formation due to creep cavitation (15). Since microalloying additions of $\mathrm{Zr}$ are beneficial to both the environmental resistance and creep resistance of $\mathrm{NiAl}$, it should also be good for fatigue resistance. However, the final impact of these competing effects on the cyclic deformation behavior of $\mathrm{NiAl}$ are too complicated to predict. Therefore, to further understand the role of microalloying additions on the behavior of $\mathrm{NiAl}$, the $1000 \mathrm{~K}$ low cycle fatigue behavior of a $\mathrm{NiAl}(0.1 \mathrm{Zr})$ alloy prepared by extrusion of prealloyed intermetallic powders was investigated. The results are compared to those of similarly processed binary $\mathrm{NiAl}$ and a $\mathrm{N}$-doped $\mathrm{NiAl}$ alloy that exhibits a slight improvement in creep strength without the large loss in tensile ductility. Differences in LCF behavior are explained by the basic differences in the deformation behavior of these three powder metallurgy (PM) alloys.

\section{MATERIALS AND EXPERIMENTAL PROCEDURES}

Vacuum atomized powders of stoichiometric $\mathrm{NiAl}$ and prealloyed powders of $\mathrm{NiAl}(\mathrm{Zr})$ and $\mathrm{NiAl}(\mathrm{N})$ were obtained from Homogeneous Metals Inc., Clayville, NY. The chemical compositions of the prealloyed powders are given in Table 1 . The nickel aluminide powders were placed in mild steel extrusion cans that were evacuated, sealed air tight, and extruded. Due to the various strengths of the alloys the powders were extruded at different temperatures but all had relatively the same grain size. The parameters employed during extrusion and the average grain size of the three alloys are listed in Table 2.

Cylindrical, dog bone-shaped fatigue samples, $13-\mathrm{mm}$ diameter by $114-\mathrm{mm}$ length, were ground from the extruded rods. The reduced gage section $(6.5 \mathrm{~mm})$ of each specimen was electropolished in a solution of $90 \%$ methanol-10\% perchloric acid at $20-25$ volts, 1 amp and 208 $\mathrm{K}$ prior to LCF testing. Fully reversed total axial strain controlled LCF tests were conducted at $1000 \mathrm{~K}( \pm 5 \mathrm{~K})$ in air, in a servohydraulic system equipped with induction heating. Strain was measured using a 13-mm gage length, clip-on, water-cooled extensometer, with alumina probes to allow testing at elevated temperatures. Temperature was measured and controlled by an infrared pyrometer. A constant total strain rate of $10^{-3} \mathrm{~s}^{-1}$ and a triangular strain-time waveform was employed for the tests conducted over a strain range of 0.2 to $1.2 \%$.

Table 1: Alloy Compositions (at.\%).

\begin{tabular}{|l|c|c|c|c|c|c|}
\hline Alloy & $\mathrm{Ni}$ & $\mathrm{Al}$ & $\mathrm{Zr}$ & $\mathrm{N}$ & $\mathrm{O}$ & $\mathrm{C}$ \\
\hline \hline $\mathrm{NiAl}$ & $50.2 \pm 0.2$ & $49.7 \pm 0.2$ & -- & 0.0009 & 0.0250 & 0.0170 \\
\hline $\mathrm{NiAl}(\mathrm{N})$ & $50.0 \pm 0.2$ & $49.9 \pm 0.2$ & -- & 0.0904 & 0.0347 & 0.0057 \\
\hline $\mathrm{NiAl}(\mathrm{Zr})$ & $49.7 \pm 0.2$ & $50.3 \pm 0.2$ & 0.094 & 0.0018 & 0.0324 & 0.0142 \\
\hline
\end{tabular}


Table 2: Materials Processing Description.

\begin{tabular}{|c|c|c|c|}
\hline Alloy & Starting Powder & Extrusion Conditions & Grain Size $(\mu \mathrm{m})$ \\
\hline \hline NiAl & Vacuum Atomized & $1200 \mathrm{~K}$ & 12 \\
Heat P2098 & $-100 /+325$ Mesh & $12: 1$ & \\
& Argon Pressurized & & 18 \\
\hline NiAl(N) & Vacuum Atomized & $1400 \mathrm{~K}$ & \\
Heat P1810 & $-100 /+325$ Mesh & $12: 1$ & 23 \\
& Nitrogen Pressurized & & \\
\hline NiAl(Zr) & Vacuum Atomized & $1500 \mathrm{~K}$ & $12: 1$ \\
Heat P1187 & -100/+325 Mesh & & \\
& Argon Pressurized & &
\end{tabular}

\section{RESULTS}

All of the $\mathrm{NiAl}$ alloys were fully dense and consisted of equiaxed grains. Fine AlN particles were present in the $\mathrm{NiAl}(\mathrm{N})$ alloy $(11)$, otherwise, the microstructure of all three nickel aluminides was quite similar. Table 3 provides the monotonic tensile properties measured for each alloy at $1000 \mathrm{~K}$, along with the monotonic brittle-to-ductile transition temperature (BDTT) based on a strain rate of $1 \times 10^{-3} \mathrm{~s}^{-1}$. The low cycle fatigue test temperature was slightly below the BDTT of $\mathrm{NiAl}(\mathrm{Zr})$ but much higher than the BDTTs of $\mathrm{NiAl}$ and $\mathrm{NiAl}(\mathrm{N})$.

Table 3: Mechanical Properties and BDTTs for PM Nickel Aluminide Alloys.

\begin{tabular}{|l|c|c|c|c|c|}
\hline Alloy & $\begin{array}{c}\text { Elastic } \\
\text { Modulus (GPa) }\end{array}$ & $\begin{array}{c}0.2 \% \text { Yield } \\
\text { Stress (MPa) }\end{array}$ & $\begin{array}{c}\text { UTS } \\
(\mathrm{MPa})\end{array}$ & $\begin{array}{c}\text { Tensile } \\
\text { Ductility (\%) }\end{array}$ & $\begin{array}{c}\text { Approximate } \\
\text { BDTT (K)* }\end{array}$ \\
\hline \hline $\mathrm{NiAl}$ & 126 & 80 & -- & $>25$ & 630 \\
\hline $\mathrm{NiAl}(\mathrm{N})$ & 150 & 94 & -- & $>25$ & 630 \\
\hline $\mathrm{NiAl}(\mathrm{Zr})$ & 200 & 320 & 328 & 0.3 & 1120 \\
\hline
\end{tabular}

${ }^{*}$ Determined for a strain rate of $1 \times 10^{-3} \mathrm{~s}^{-1}$.

The LCF life is plotted versus total strain range in Fig. 1. The total strain fatigue resistance of $\mathrm{NiAl}(\mathrm{N})$ was higher than binary $\mathrm{NiAl}$ in the range of strain amplitudes examined. Zirconium additions were even more beneficial for fatigue life at total strain ranges below $0.38 \%$. However, on increasing the strain range from $0.38 \%$ to $0.40 \%$, the $\mathrm{Zr}$-doped alloy exhibited a drastic reduction in life due to rapid exhaustion of its already limited tensile ductility.

The stress response curves, which represent the locus of peak tensile stresses with successive cycles, are depicted in Fig. 2. There are clear and dramatic differences between the $\mathrm{Zr}$ doped and both the $\mathrm{NiAl}$ and $\mathrm{NiAl}(\mathrm{N})$ materials. First, $\mathrm{NiAl}(\mathrm{Zr})$ displayed much larger response stresses than the other two alloys. Second, $\mathrm{NiAl}(\mathrm{Zr})$ exhibited a short period of cyclic hardening and attained a maximum stress in the very early stages of cyclic life. Beyond the maximum stress value, a gradual softening took place prior to a regime of nearly stable stress response. Also, the initial hardening period was prolonged with decreasing strain range. Conversely, $\mathrm{NiAl}$ and $\mathrm{NiAl}(\mathrm{N})$ experienced cyclic softening initially. This was followed by a period of stable stress response that continued until the tensile stress amplitude decreased rapidly due to the formation of macrocracks and their subsequent growth, which immediately preceded failure. Half-life cyclic 
stress-strain curves (Fig. 3) of all the $\mathrm{NiAl}$ alloys could be represented by a power law relationship $\Delta \sigma / 2=K^{\prime}\left(\Delta \varepsilon_{\mathrm{p}} / 2\right)^{n^{\prime}}$, where $K^{\prime}$ and $n^{\prime}$ are the cyclic strength coefficient and cyclic hardening exponent, respectively. $\mathrm{Zr}$-doping significantly improved cyclic strength and led to a high $\mathbf{n}$ ', while the effect of nitrogen was only marginal on these properties.

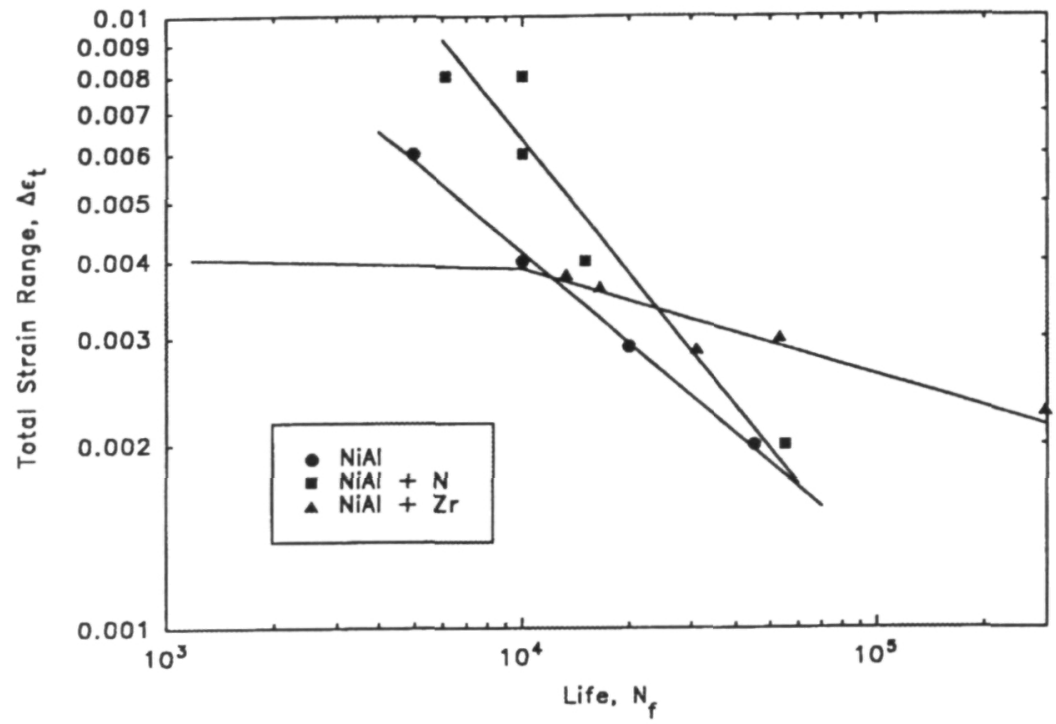

Fig. 1. Fatigue life versus total strain range for PM nickel aluminide alloys at $1000 \mathrm{~K}$.

HIGH STRAIN

LOW STRAIN
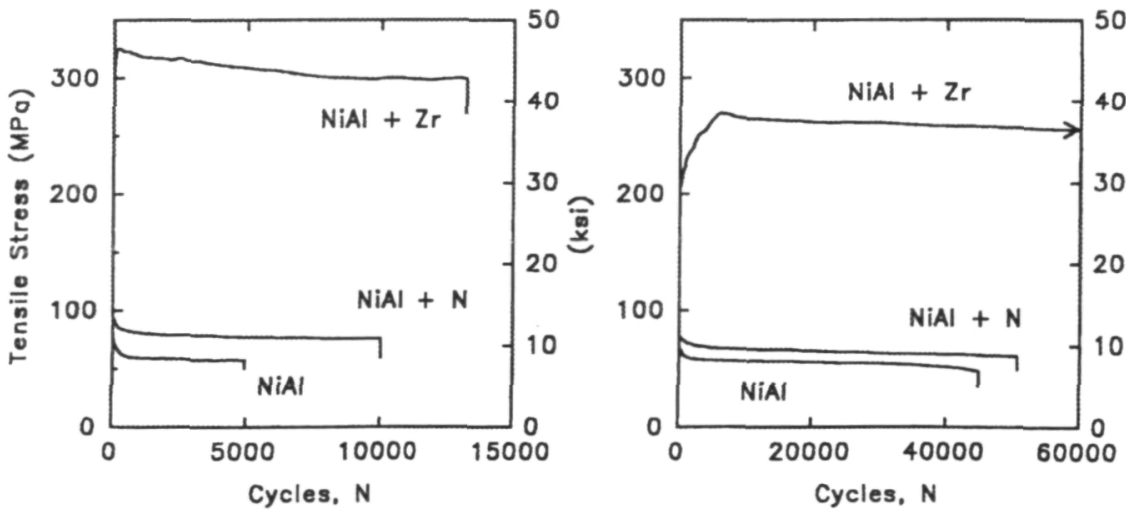

Fig. 2. Typical stress response curves for $\mathrm{PM} \mathrm{NiAl}$ alloys at high and low strain ranges. 


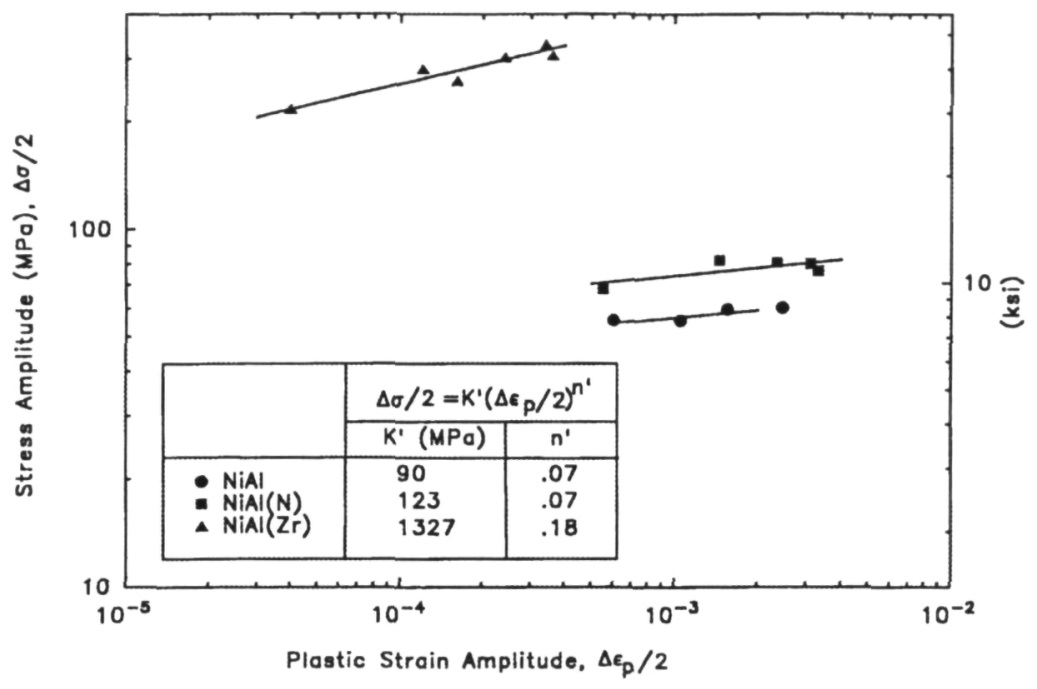

Fig. 3. Cyclic stress-strain curves for PM NiAl alloys at $1000 \mathrm{~K}$.

\section{DISCUSSION}

The low cycle fatigue behavior of the three $\mathrm{NiAl}$ alloys is heavily influenced by the relation between test temperature and their respective BDTTs. For NiAl( $\mathrm{Zr})$, the test temperature was just below its BDTT, therefore, recovery was not significant, and this led to the higher and more homogeneous dislocation structure that was observed within the grains (16). Additionally, $\mathrm{Zr}$ atoms are very effective in pinning dislocations below the BDTT (12-14) and increasing the viscous drag force on dislocations at higher temperatures (9). Consequently, the mutual interactions between dislocations and the solid solution hardening due to the $\mathrm{Zr}$ atoms resulted in significantly higher cyclic stresses and a high $\mathrm{n}$ :. Because the BDTT of the binary and N-doped alloys was much lower than the test temperature, significant recovery was able to occur during testing resulting in a lower $\mathrm{n}^{\prime}$. The marginal improvement in cyclic stress response and $\mathrm{n}^{\circ}$ of the $\mathrm{N}$-doped alloy over the binary $\mathrm{NiAl}$ is assumed to be the result of dislocation pinning by the finely dispersed AIN particles in the former alloy.

The two stages in the total strain-life plot of $\mathrm{NiAl}(\mathrm{Zr})$ occurred as a result of the change in fracture behavior from slow and stable intergranular crack growth at strain ranges $\leq 0.38 \%$ to brittle cleavage-dominated overload fracture at larger strain ranges. At strain ranges above $0.38 \%$, the peak tensile stress reached the monotonic cleavage stress of the $\mathrm{Zr}$-doped alloy (328 $\mathrm{MPa}$ ) in less than 100 cycles, enabling fast crack growth by transgranular cleavage (16). At total strain ranges $\leq 0.38 \%$, the peak tensile cyclic stresses remained at a much lower level than the cleavage fracture stress. In general, fatigue lives are governed by the ductility of the material at high strains and by its strength at low strains. The longer lives of $\mathrm{NiAl}(\mathrm{Zr})$ at low strain ranges result from its basic capacity to resist the applied strains on the basis of high strength. Both the $\mathrm{NiAl}$ and $\mathrm{NiAl}(\mathrm{N})$ have shorter lives at low strain ranges due to the synergistic interaction between fatigue and creep. A higher slope for the strain range-life plot of the $\mathrm{NiAl}(\mathrm{N})$ reflects 
this interaction. In order to improve the fatigue resistance of the binary and N-doped alloy, the grain boundaries need to be strengthened to reduce grain boundary sliding and the associated intergranular wedge cracking that was observed in these two alloys. Since $\mathrm{Zr}$ segregates to the grain boundaries in $\mathrm{NiAl}(13)$ and apparently strengthens the boundary regions preventing grain boundary sliding, $\mathrm{NiAl}(\mathrm{Zr})$ does not suffer from this same problem as the other two PM alloys.

\section{CONCLUSIONS}

There were only very minor differences in the fatigue behavior of binary $\mathrm{NiAl}$ and $\mathrm{NiAl}(\mathrm{N})$ alloys. However, $\mathrm{Zr}$ additions significantly altered the fatigue behavior of $\mathrm{NiAl}$ at $1000 \mathrm{~K}$. The $\mathrm{Zr}$ additions led to a change in the basic deformation behavior of the material such that the fatigue test temperature was just below the BDTT of the alloy instead of significantly above the BDTT as in the other two PM alloys. $\mathrm{Zr}$ also increases the tensile flow stress and results in higher response stresses under strain controlled cyclic loading. Furthermore, $\mathrm{Zr}$ segregates to the grain boundaries and prevents intergranular sliding and as a consequence increases the fatigue life of the alloy at low strain ranges where the interactions between creep, fatigue and oxidation control life. However, at higher strain ranges the cyclic response stresses quickly exceed the cleavage strength of the alloy resulting in significantly shortened fatigue lives.

\section{REFERENCES}

1. D.B. Miracle, Acta Metall. Mater. 39, 649 (1993).

2. R.D. Noebe, R.R. Bowman and M.V. Nathal, Inter. Mater. Rev. 38, 193 (1993).

3. R. Darolia, JOM 43(3), 44 (1991).

4. C.T. Liu and K.S. Kumar, JOM 45(5), 38 (1993).

5. R. Darolia, D. Lahrman and R.D. Field, Scripta Metall. Mater. 26, 1007 (1992).

6. R.D. Noebe and M.K. Behbehani, Scripta Metall. Mater. 27, 1795 (1992).

7. I.E. Locci, R. Dickerson, R.R. Bowman, J.D. Whittenberger, M.V. Nathal, and R. Darolia, in High Temperature Ordered Intermetallic Alloys V, eds. I. Baker et al., Vol. 288, Materials Research Society, Pittsburgh, PA, pp. 685-690 (1993).

8. W.S. Walston, R.D. Field, J.R. Dobbs, D.F. Lahrman, and R. Darolia, in International Symposium on Structural Intermetallics, eds. R. Darolia et al., TMS, Warrendale, PA, pp. 523532 (1993).

9. J.D. Whittenberger and R.D. Noebe, submitted to Metall. Mater. Trans. A, (1995).

10. J.D. Whittenberger, R.D. Noebe and D.R. Wheeler, to be published in High Temperature Ordered Intermetallic Alloys VI, eds. J. Horton et al., Materials Research Society, Pittsburgh, PA, (1995).

11. R.D. Noebe and A Garg, Scripta Metall. Mater. 30, 815 (1994).

12. R.R. Bowman, R.D. Noebe, S.V. Raj and I.E. Locci, Metall. Trans. A 23A, 1493 (1992).

13. M.V. Zeller, R.D. Noebe and I.E. Locci, in HITEMP Review - 1990, NASA CP-10051, pp. 21-1 to 21-17 (1990).

14. R.D. Noebe, NASA TM-106534, April 1994.

15. B.A. Lerch and R.D. Noebe, Metall. Maters. Trans. A 25A, 309 (1994).

16. K.B.S. Rao, B.A. Lerch and R.D. Noebe, in HITEMP Review - 1994, NASA CP-10146, pp. 53-1 to 53-11 (1994). 